\title{
Hospital readmission following transplantation: identifying risk factors and designing preventive measures
}

\author{
Dorothy R McKenna, MS, ${ }^{a}$ Matthew R Sullivan, MD, ${ }^{a}$ John M Hill, MD, ${ }^{\text {ab }}$ Christopher \\ $\mathrm{H}$ Lowrey, MD, ${ }^{\text {ac }}$ Jeremiah R Brown, $\mathrm{PhD},{ }^{\text {de }}$ Joshua Hickman, MHA, ${ }^{\mathrm{a}}$ and Kenneth $\mathrm{R}$ \\ Meehan, MD ${ }^{\mathrm{ab}}$
}

${ }^{a}$ Blood and Marrow Transplant Program, Norris Cotton Cancer Center; ${ }^{b}$ Department of Medicine; ${ }^{\mathrm{c} D e p a r t m e n t}$ of Pharmacology

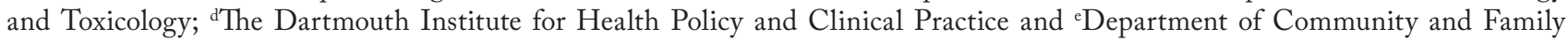
Medicine, at the Geisel School of Medicine, Dartmouth College, Hanover, New Hampshire

\begin{abstract}
Background About 1 in 7 of all hospitalized patients is readmitted within 30 days of discharge. The cost of readmissions is significant, with Medicare readmissions alone costing the health care system an estimated $\$ 28$ billion a year.

Objective To identify the rates of and causes for readmission within 100 days of patients receiving a hematopoietic stem cell transplant.

Methods We performed a retrospective review of 235 consecutive transplant recipients (autologous, $n=144 ;$ allogeneic, $n=91$ ) to determine rates and causes for readmission within 100 days of patients receiving a transplant. Medical records and hospital readmissions were reviewed for each patient.

Results 36 allogeneic patients accounted for 56 readmissions. 23 autologous patients accounted for 26 readmissions. Autologous transplant recipients were most commonly readmitted for the development of a fever ( $n=15$ patients) or cardiopulmonary issues ( $\mathrm{n}$ $=4)$. The most prevalent reasons for readmission in the allogeneic recipients included a fever $(n=21)$ or the development or exacerbation of graft-versus-host disease $(n=5)$. The readmission length of stay was 6 days (median range, $1-91$ days) for allogeneic patients and 4 days (median range, 1-22 days) for autologous patients. There was no difference in survival between the readmitted and the non-readmitted cohorts $(P=.55$ for allogeneic patients; $P=.24$ for autologous patients). Although allogeneic graft recipients demonstrated a higher readmission rate (39.6\%) compared with autologous recipients (16\%), none of the variables examined, including age, gender, performance status, diagnosis, remission status at the time of transplant, comorbidities, type of preparative chemotherapy regimen or donor type, identified patients at increased risk for readmission.

Limitations Variations in clinical care, physician practices, and patient characteristics need to be considered when examining readmission rates. Most of the allogeneic patient population included unrelated donor recipients (65\%) who received nonmyeloablative conditioning regimens (81\% of allogeneic recipients). These features may not be characteristic of other centers.

Conclusions In these high-risk patients, readmissions following a transplant are common. Enhanced predischarge education by nurses and pharmacists, along with ongoing outpatient education and rigorous outpatient follow-up through phone calls or social media may decrease readmission rates.
\end{abstract}

A bout 1 in 7 of all patients is readmitted within 30 days of hospital discharge. ${ }^{1}$ However, readmission rates vary, depending on the underlying diagnosis, patient characteristics, variation in patient care among care givers, and geography. ${ }^{2-7}$ The cost of readmissions is astonishing, with Medicare readmissions alone costing the health care system an estimated $\$ 28$ billion a year. ${ }^{1}$

The Affordable Care Act sanctions Medicare to reduce a hospital's payments if the hospital demonstrates excessive readmission rates. The optimal readmission rates used by Centers for Medicare \&
Medicaid Services (CMS) is the 30-day readmission rate less than or equal to the 80th percentile. This federal program was initially imposed on 3 diagnoses - pneumonia, congestive heart failure, and myocardial infarction. Additional diagnoses were added in 2014 and included hip or knee arthroplasty and chronic obstructive pulmonary disease. ${ }^{2}$

Hematopoietic stem cell transplantation (HSCT) can significantly extend life and potentially cure patients. An estimated 20,000 people in the United States received an HSCT in 2010, demonstrating a marked increase over the past 20 years. ${ }^{8}$ In addi-

Accepted for publication April 13, 2015. Correspondence: Kenneth R Meehan, MD; Kenneth.R.Meehan@hitchcock.org. Disclosures: The authors have no disclosures. JCSO 2015;13:316-322. (2) 2015 Frontline Medical Communications. DOI 10.12788/jcso.0168. 
tion, HSCT is an expensive procedure, with an autologous transplant costing $\$ 61,000-\$ 88,000$, and an unrelated allogeneic transplant costing $\$ 200,000$ or more. ${ }^{9-13}$ According to the Agency for Healthcare Research and Quality, bone marrow transplantation was identified as the procedure associated with the most rapidly rising hospital costs during 2004-2007..$^{14}$

The ability to identify risk factors that predict posttransplant adverse effects would enable clinicians to monitor high-risk patients more aggressively and to intervene earlier to prevent readmission. Given the emphasis on cost containment in the setting of declining reimbursements, we sought to examine readmission rates among HSCT patients by looking at the causes and risk factors for readmission within 100 days of a patient receiving a stem cell transplant over a period of 5 years. Our results offer a unique opportunity to examine these critical factors in anticipation of identifying high-risk patients. These findings could allow for the standardization of post-transplant care to minimize complications and optimize outcomes while decreasing the number of readmissions.

\section{Methods}

\section{Patient population}

Patients who received either an autologous or allogeneic hematopoietic stem cell transplant between January 2007 and May 2012 at Dartmouth-Hitchcock Medical Center (DHMC) were included in the study. Each patient signed an internal review board-approved informed consent allowing use of their clinical data.

\section{The program and medical center}

The Norris Cotton Cancer Center is a National Cancer Institute-designated comprehensive cancer center that is a part of the DHMC and located in a rural setting. The Blood and Marrow Transplant Program is accredited by the Foundation for the Accreditation of Cellular Therapy for autologous and allogeneic transplantations, the Center for International Blood and Marrow Transplant Research, and the National Marrow Donor Program.

\section{Definition of 'readmission'}

We sought to identify the number of patients readmitted and the number of readmissions. Any transplant patient who was readmitted to a hospital, either DHMC or another hospital, within 100 days of receiving a transplant was identified. For those patients who received an outpatient autologous transplant, the planned readmission within 20 days of the transplant was not included. Readmission for relapse was not included.

Medical records from each readmission hospital course were reviewed by a physician to identify the reason or reasons for readmission, the length of stay, the clinical course during the hospital stay, and the outcome (eg, discharge, death). If there was more than 1 cause for readmission, then the reviewing physician used clinical judgment to select the major reason for readmission. If a patient was transferred to DHMC from an outside hospital, then the 2 readmissions were combined and interpreted as a single readmission. If a patient experienced more than 1 readmission within 100 days of transplant, then the first admission was included in the comparative analysis, but the number of readmissions for each patient was reported.

\section{Data abstraction and statistical analyses}

Data collection focused on patient demographics, primary diagnosis and remission status at the time of transplant, details of the initial transplant hospitalization, preparative chemotherapy regimen, type of donor (allogeneic), hospital readmission or readmissions following transplant, length of stay for readmission, and survival. Information was abstracted from the medical records by a data manager and verified by a physician. These data were analyzed using Stata11 (StatCorp LP, College Station, TX).

Comparisons were made between patients readmitted within 100 days of receiving a transplant, and those patients who were not readmitted, using the Student $t$ test for continuous variables and the chi-square test for categorical variables. The variables tested included patient's age, gender, diagnosis, disease status at the time of transplant, and Karnofsky Performance Status Scale score at the time of transplant. The Hematopoietic Cell TransplantationSpecific Comorbidity Index (HCT-CI), is a weighted scoring system, with 15 comorbid conditions assessed, that predicts nonrelapse mortality following transplant. Each condition is given 1 point. The higher the score, the higher the risk of a patient dying from a comorbid condition rather than the transplant or the hematologic malignancy. The scores range from $0-4$, with a higher score denoting a lower chance of survival. For example, patients with a score of 0 have a $14 \%$ chance of dying from another condition at 2 years, and those with a score of 4 have a $40 \%$ chance of dying from another condition at 2 years. ${ }^{15}$ For allogeneic recipients, the donor type (related vs unrelated) and the preparative regimens (myeloablative vs nonmyeloablative) were also evaluated.

\section{Results}

\section{Patient characteristics}

Between January 2007 and May 2012, 235 patients received transplants. There were 144 autologous and 91 allogeneic transplant recipients (Table 1 ). The majority of the allogeneic recipients had leukemia $(n=51)$, followed by lymphoma $(\mathrm{n}=28)$, myelodysplasia or myeloproliferative disease (MDS/MPD; $n=8)$, myeloma $(n=1)$, or other diseases (aplastic anemia, $\mathrm{n}=1$; paroxysmal nocturnal hemo- 
TABLE 1 Patient characteristics

\begin{tabular}{|c|c|c|}
\hline \multirow[b]{2}{*}{ Characteristic } & \multicolumn{2}{|c|}{ Type of transplant } \\
\hline & $\begin{array}{l}\text { Allogeneic } \\
(n=91)\end{array}$ & $\begin{array}{l}\text { Autologous } \\
(\mathrm{n}=144)\end{array}$ \\
\hline Mean age at transplant, y & 49.1 & 53.6 \\
\hline $\begin{array}{l}\text { Sex, n (\%) } \\
\text { Male } \\
\text { Female }\end{array}$ & $\begin{array}{l}47(51.7) \\
44(48.3)\end{array}$ & $\begin{array}{l}90(62.5) \\
54(37.5)\end{array}$ \\
\hline $\begin{array}{l}\text { Diagnosis, n (\%) } \\
\text { Leukemia } \\
\text { Lymphoma } \\
\text { Multiple myeloma } \\
\text { MDS/MPD } \\
\text { Other }\end{array}$ & $\begin{aligned} 51 & (56.0) \\
28 & (30.8) \\
1 & (1.1) \\
8 & (8.8) \\
3 & (3.3)\end{aligned}$ & $\begin{array}{c}9(6.3) \\
69(47.9) \\
65(45.1) \\
- \\
1(0.7)\end{array}$ \\
\hline $\begin{array}{l}\text { Disease status at transplant, } \mathrm{n}(\%) \\
\text { Complete response } \\
\text { Not in complete response }\end{array}$ & $\begin{array}{l}55(60.4) \\
36(39.6)\end{array}$ & $\begin{array}{l}89(61.8) \\
55(38.2)\end{array}$ \\
\hline $\begin{array}{l}\text { Karnofsky Performance Status } \\
\text { Scale score at transplant (mean) }\end{array}$ & 83.0 & 85.6 \\
\hline $\begin{array}{l}\mathrm{HCT}-\mathrm{Cl}, \mathrm{b} \text { n (\%) } \\
0 \\
1 \\
2 \\
\geq 3\end{array}$ & $\begin{array}{l}44(48.3) \\
7(7.7) \\
13(14.3) \\
27(29.7)\end{array}$ & $\begin{array}{l}93(64.6) \\
25(17.4) \\
11(7.6) \\
15(10.4)\end{array}$ \\
\hline $\begin{array}{l}\text { Donor type, n (\%) } \\
\text { Related } \\
\text { Unrelated }\end{array}$ & $\begin{array}{l}32(35.2) \\
59(64.8)\end{array}$ & $\begin{array}{l}\text { na } \\
\text { na }\end{array}$ \\
\hline $\begin{array}{l}\text { Preparative regimen, } \mathrm{n}(\%) \\
\text { Myeloablative } \\
\text { Nonmyeloablative }\end{array}$ & $\begin{array}{l}17(18.7) \\
74(81.3)\end{array}$ & $\begin{array}{l}\text { na } \\
\text { na }\end{array}$ \\
\hline $\begin{array}{l}\text { MDS, myelodysplastic syndrome; MPD, myel } \\
\text { HCT-CI, Hematopoietic Cell Transplantation-S }\end{array}$ & $\begin{array}{l}\text { liferative disorde } \\
\text { ific Comorbidity }\end{array}$ & not applicable; \\
\hline $\begin{array}{l}\text { aThe Karnofsky Performance Status Scale scor } \\
\text { daily activities. A score of } 100 \text { denotes the ab } \\
\text { lems, whereas a score of } 80 \text { means duties car } \\
\text { erally due to signs or symptoms of the disease } \\
\text { with } 15 \text { comorbid conditions assessed, that pr } \\
\text { plant. Each condition is given } 1 \text { point. The hig } \\
\text { dying from a comorbid condition, rather than } \\
\text { malignancy. The scores p rovide an assessmer } \\
\text { score of } 0=14 \% \text { nonrelapse mortality at } 2 \text { ye }\end{array}$ & $\begin{array}{l}\text { valuates a patien } \\
\text { y to perform daily } \\
\text { e performed but } r \\
\text { The HCT-Cl is a v } \\
\text { icts nonrelapse } m \\
r \text { the score, the } h i \\
m \text { the transplant } \\
\text { f nonrelapsed } m \\
s, 1=22 \%, 2=\end{array}$ & $\begin{array}{l}\text { ility to perform } \\
\text { vities without prob- } \\
\text { e some effort, gen- } \\
\text { ted scoring system, } \\
\text { ity following trans- } \\
\text { the risk of a patient } \\
\text { hematologic } \\
\text { ly at } 2 \text { years, with a } \\
\text { and } \geq 3=41 \% \text {. }\end{array}$ \\
\hline
\end{tabular}

globinuria, $\mathrm{n}=1$; medulloblastoma, $\mathrm{n}=1$ ). Most of the allogeneic recipients $(60.4 \%)$ were in complete remission at the time of transplant. The majority of patients $(64.8 \%)$ received an unrelated transplant. Most allogeneic recipients received a nonmyeloablative conditioning regimen (81.3\%). Forty patients (44.0\%) demonstrated an HCT-CI score of 2 or more at the time of transplant, that is, they had a $19 \%$ chance of dying from a comorbid condition at 2 years following transplantation. For the 91 allogeneic transplant recipients, initial hospitalization was 28 days (median range, 1-122 days).

Autologous transplant recipients included patients with lymphoma ( $n=69)$, myeloma $(n=65)$, leukemia $(n=9)$, or other $(n=1)$. At the time of transplant, most of the autologous patients were in complete remission (61.8\%). Ninety-three patients (64.6\%) demonstrated a transplant comorbidity index of 0 , and 26 patients (18\%) had a transplant comorbidity index of 2 or greater. For the 144 autologous recipients, initial hospitalization was 18 days (median range, 1-31 days).

\section{Readmissions}

Allogeneic transplant recipients. Of the 91 allogeneic transplant recipients, 36 (39.6\%) were readmitted within 100 days of transplant (Table 2). The readmitted patients had leukemia ( $n=19)$, lymphoma $(n=12)$, MDS/MPD $(n=3)$, or other diagnoses $(n=2)$. Most of the allogeneic recipients who were readmitted were in complete remission at the time of transplant (61.1\%). The HCT-CI scores at the time of transplant for the readmitted patients were variable, with scores of $0(n=16), 1(n=4), 2(n=5)$, or $\geq 3$ ( $n=11)$. Of the readmitted allogeneic patients, more patients had received an unrelated transplant (72.2\%) compared with a related transplant. Most readmitted allogeneic recipients were treated with a nonmyeloablative conditioning regimen $(80.5 \%)$. In related donor transplant recipients, 10 of 32 patients $(31.2 \%)$ were readmitted, and in unrelated donor transplants, 26 of 59 patients (44.1\%) were readmitted. Of the 91 allogeneic transplant recipients, 2 patients received their transplant as outpatients. Neither of those 2 patients experienced unplanned readmissions following transplantation.

Autologous transplant recipients. Of the 144 autologous transplant recipients, 23 patients $(16.0 \%)$ were readmitted within 100 days of transplant (Table 3 ). These patients had either lymphoma $(n=15)$ or myeloma $(n=8)$. The HCT-CI score at the time of transplant did not correlate with readmission, since 14 patients with a comorbidity score of zero were readmitted. The majority of the readmitted patients $(65.2 \%)$ were disease-free at the time of their transplant. Of the 144 autologous transplant recipients, 9 patients received their transplant as outpatients. None of those patients experienced unplanned readmissions following transplantation.

\section{Variables associated with readmission}

Patient characteristics (age, gender, performance status), disease traits, type of preparative chemotherapy regimen, and donor type were examined to determine if differences existed between patients readmitted and patients who were not readmitted (allogeneic, Table 2; autologous, Table 3). None of the variables were significantly associated with readmission, for either the allogeneic or autologous transplant recipients. Three of the autologous recipients who were readmitted for a fever experienced a documented 
TABLE 2 Risk factors for readmission in allogeneic recipients ${ }^{a}(n=91)$

\begin{tabular}{|c|c|c|c|}
\hline Risk factor & $\begin{array}{l}\text { Readmitted } \\
(n=36)\end{array}$ & $\begin{array}{l}\text { Not readmitted } \\
(n=55)\end{array}$ & P value* \\
\hline Mean age at transplant, y & 48.8 & 49.3 & .8457 \\
\hline \multicolumn{4}{|l|}{ Gender, n (\%) } \\
\hline $\begin{array}{l}\text { Male } \\
\text { Female }\end{array}$ & $\begin{array}{l}20(55.6) \\
16(44.4)\end{array}$ & $\begin{array}{l}27(49.1) \\
28(50.9)\end{array}$ & .546 \\
\hline \multicolumn{4}{|l|}{ Diagnosis, n (\%) } \\
\hline $\begin{array}{l}\text { Leukemia } \\
\text { Lymphoma } \\
\text { Multiple myeloma } \\
\text { MDS/MPD } \\
\text { Other }\end{array}$ & $\begin{array}{c}19(52.8) \\
12(33.3) \\
0(0) \\
3(8.3) \\
2(5.6)\end{array}$ & $\begin{aligned} 32 & (58.2) \\
16 & (29.1) \\
1 & (1.8) \\
5 & (9.1) \\
1 & (1.8)\end{aligned}$ & .767 \\
\hline \multicolumn{4}{|l|}{ Disease status at transplant, $\mathrm{n}(\%)$} \\
\hline $\begin{array}{l}\text { Complete response } \\
\text { Not in complete response }\end{array}$ & $\begin{array}{l}22(61.1) \\
14(38.9)\end{array}$ & $\begin{array}{l}33(60.0) \\
22(40.0)\end{array}$ & .916 \\
\hline $\begin{array}{l}\text { Karnofsky Performance Status } \\
\text { Scale score at transplant (mean) }\end{array}$ & 83.6 & 83.1 & .8099 \\
\hline \multicolumn{4}{|l|}{ HCT-Cl, ${ }^{c}$ n (\%) } \\
\hline $\begin{array}{l}0 \\
1 \\
2 \\
\geq 3\end{array}$ & $\begin{array}{c}16(44.4) \\
4(11.1) \\
5(13.9) \\
11(30.6)\end{array}$ & $\begin{array}{c}28(50.9) \\
3(5.5) \\
8(14.6) \\
16(29.1)\end{array}$ & .773 \\
\hline \multicolumn{4}{|l|}{ Donor type, n (\%) } \\
\hline $\begin{array}{l}\text { Related } \\
\text { Unrelated }\end{array}$ & $\begin{array}{l}10(27.8) \\
26(72.2)\end{array}$ & $\begin{array}{l}22(40.0) \\
33(60.0)\end{array}$ & .232 \\
\hline \multicolumn{4}{|l|}{ Preparative regimen, n (\%) } \\
\hline $\begin{array}{l}\text { Myeloablative } \\
\text { Nonmyeloablative }\end{array}$ & $\begin{array}{l}7(19.4) \\
29(80.6)\end{array}$ & $\begin{array}{l}10(18.2) \\
45(81.8)\end{array}$ & .880 \\
\hline
\end{tabular}

MDS, myelodysplastic syndrome; MPD, myeloproliferative disorder; HCT-Cl, Hematopoietic Cell Transplantation-Specific Comorbidity Index

aBased on a univariable analysis. 'The Karnofsky Performance Status Scale score evaluates a patient's ability to perform daily activities. A score of 100 denotes the ability to perform daily activities without problems, whereas a score of 80 means duties can be performed but require some effort, generally due to signs or symptoms of the disease. 'The HCT-Cl is a weighted scoring system, with 15 comorbid conditions assessed, that predicts nonrelapse mortality following transplant. Each condition is given 1 point. The higher the score, the higher the risk of a patient dying from a comorbid condition, rather than from the transplant or the hematologic malignancy. The scores provide an assessment of nonrelapsed mortality at 2 years, with a score of $0=14 \%$ nonrelapse mortality at 2 years, $1=22 \%, 2=19 \%$, and $\geq 3=41 \%$.

* $P$ value examines if differences exist between patients who were readmitted and those who were not readmitted.

infection during their initial hospital transplant course. A documented infection was defined as an infection confirmed by culture of body fluid, urine or blood. Six of the allogeneic patients who were readmitted experienced a documented infection during their initial hospital transplant course.

Each autologous and allogeneic patient had an indwelling catheter placed at the beginning of their transplant course. For the autologous recipients, catheters are removed prior to discharge. For each allogeneic recipient, tunneled catheters were left in place at the time of discharge and were generally removed 30-90 days following discharge, based on the patient's clinical course. The persistent use of the indwelling catheters in allogenic recipients may have contributed to the $58 \%$ of allogeneic patients who were readmitted with a fever. Of the 21 allogeneic patients readmitted for fever or infection, 4 were readmitted for documented blood stream infections, perhaps contributed by the indwelling central line.

Overall survival was also analyzed for patients readmitted and those patients who were not readmitted. Among both the allogeneic and autologous recipients, there was 
TABLE 3 Risk factors for readmission in autologous recipients ${ }^{a}(n=144)$

\section{Risk factor} ( $\mathrm{n}=\mathbf{2 3}$ )

47.3

\section{Not readmitted ( $n=121$ )}

54.8
$11(47.8)$

$12(52.2)$
79 (65.3) $42(34.7)$

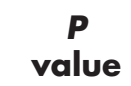

.0100

$\begin{array}{lcc}\text { Sex, } n(\%) & \\ \text { Male } & 11(47.8) & 79(65.3) \\ \text { Female } & 12(52.2) & 42(34.7) \\ \text { Diagnosis, n (\%) } & \\ \text { Leukemia } & 0(0) & 9(7.4) \\ \text { Lymphoma } & 15(65.2) & 54(44.6) \\ \text { Multiple myeloma } & 8(34.8) & 57(47.1) \\ \text { MDS/MPD } & - & - \\ \text { Other } & 0(0) & 1(0.8)\end{array}$

Disease status at transplant, $n(\%)$

Complete response

Not in complete response

$15(65.2)$

$8(34.8)$

$74(61.2)$ $47(38.8)$

.713

Karnofsky Performance Status Scale score at transplant (mean)

85.4

8543

$\mathrm{HCT}-\mathrm{Cl},{ }^{\mathrm{c}} \mathrm{n}(\%)$

$\begin{array}{lcc}0 & 14(60.9) & 79(65.3) \\ 1 & 4(17.4) & 21(17.4) \\ 2 & 1(4.4) & 10(8.3) \\ \geq 3 & 4(17.4) & 11(9.1)\end{array}$

MDS, myelodysplastic syndrome; MPD, myeloproliferative disorder; $\mathrm{HCT}-\mathrm{Cl}$, Hematopoietic Cell TransplantationSpecific Comorbidity Index

aBased on a univariable analysis. 'The Karnofsky Performance Status Scale score evaluates a patient's ability to perform daily activities. A score of 100 denotes the ability to perform daily activities without problems, whereas a score of 80 means duties can be performed but require some effort, generally due to signs or symptoms of the disease. cThe $\mathrm{HCT}-\mathrm{Cl}$ is a weighted scoring system, with 15 comorbid conditions assessed, that predicts nonrelapse mortality following transplant. Each condition is given 1 point. The higher the score, the higher the risk of a patient dying from a comorbid condition, rather than from the transplant or the hematologic malignancy. The scores provide an assessment of nonrelapsed mortality at 2 years, with a score of $0=14 \%$ nonrelapse mortality at 2 years, $1=22 \%, 2=19 \%$, and $\geq 3=41 \%$

* $P$ value examines if differences exist between patients who were readmitted and those who were not readmitted.

\section{Readmitted}

gastrointestinal signs and symptoms ( $\mathrm{n}$ $=1$ ), or other problems (allergic reaction, $\mathrm{n}=1$; tacrolimus toxicity, $\mathrm{n}=2$; psychiatric condition, $\mathrm{n}=1$ ).

Of the 36 allogeneic transplant recipients who were readmitted, 22 patients were admitted once, 10 were admitted twice, and 2 were readmitted 3 or 4 times, respectively (Table 4). Therefore, 36 patients accounted for 56 readmissions. The time to readmission following an allogeneic stem cell transplant was 43 days (median range, 16-95 days). The length of stay for each readmission was 6 days (median range, 1-91 days).

Autologous recipients. The most prevalent cause for readmission for recipients of an autologous transplant was fever $(\mathrm{n}=15$; Table 4). However, an organism was isolated in only 4 patients (bacteria, $\mathrm{n}=2$; fungus, $\mathrm{n}=1$; mixed organisms, $n=1$ ). Additional reasons for readmission included cardiopulmonary issues $(n=4)$, gastrointestinal signs and symptoms $(n=2)$, electrolyte abnormalities $(\mathrm{n}=1)$, and other $(\mathrm{n}=$ 1 ; pain and weakness due to radiation myelitis).

Of the 23 autologous transplant recipients who were readmitted, 21 patients were admitted once, 1 was admitted twice, and 1 was readmitted 3 times (Table 5). Therefore, 23 patients accounted for 26 readmissions. The time to readmission following an autologous stem cell transplant was 35 days no difference in survival when comparing the group of patients who were readmitted and the patients who did not require readmission $(P=.55$ for allogeneic patients; $P=.24$ for autologous patients).

\section{Causes for readmissions}

Allogeneic recipients. The most prevalent cause for readmission in allogeneic transplant patients was the development of a fever (58.3\%) (Table 4). Of these 21 patients who developed a fever, 16 patients had an organism identified. Isolated organisms included bacteria $(n=8)$, virus $(n=3)$ or mixed infections involving more than one type of organism ( $\mathrm{n}=5$ patients). Additional reasons for readmission included the development of or the exacerbation of graft versus host disease $(\mathrm{n}=5)$, cardiopulmonary problems (n $=2)$, electrolyte abnormalities $(n=2)$, renal issues $(n=1)$, (median range, 14-95 days). The length of stay for each readmission was 4 days (median range, 1-22 days).

\section{Discussion}

Posttransplant care in the outpatient setting requires frequent office visits with laboratory analyses, the performance of numerous radiographs, and prescribing many medications. Each of these factors incurs significant costs to the patient and society. There is variability in outpatient care following discharge, due to physician preferences, the location or geography of the transplant center, the underlying disease, and complications associated with transplant. This variability has an impact on both patients and payers. Our results indicate that almost $40 \%$ of allogeneic transplant recipients and $16 \%$ of autologous transplant recipients were readmitted within 100 days of transplant, with fever being 
the most common cause for readmission. Despite the differences in the treatment and the clinical course of autologous and allogeneic transplant recipients, the median time to readmission following transplant was comparable, at 43 days following an allogeneic transplant and 35 days following an autologous transplant. Once patients had been readmitted, the median length of stay was similar in both groups: 6 days for allogeneic patients and 4 days for autologous transplant patients. Among both the allogeneic and autologous recipients, there was no difference in survival when comparing the patients who were readmitted and the patients who did not require readmission. After evaluating patient characteristics, disease type, donor type and type of induction chemotherapy, we found that none of those traits defined characteristics of a high-risk group of patients requiring readmission.

Little is known about readmission rates in highly specialized areas. In the few published studies that exist, readmission rates range from $30 \%$ for kidney transplant recipients to $45 \%$ for liver transplant recipients. ${ }^{16,17}$ Few publications examine readmission rates following hematopoietic stem cell transplantation. ${ }^{5,18-21}$ A recent study examined readmission rates in 91 allogeneic recipients who received non-myeloablative chemotherapy. ${ }^{5}$ Thirty-eight percent of patients were readmitted. Multivariate analysis identified the development of an infection during the transplant course as the only risk factor that predicted an increased risk for readmission. One study examining autologous transplant recipients identified that patient's age and pretransplant co-morbidities were predictive of readmission. ${ }^{21}$ Despite these findings, our relatively large patient cohort failed to identify patient characteristics associated with increased risk of posttransplant readmission. Our results confirm published findings that the readmission rates for allogeneic transplant recipients range from 38\%-40\%.,18

The strength of this review is the analysis of a large patient population of consecutive autologous or allogeneic transplant recipients over 5 years. The 100 -day readmission time frame was selected to provide an accurate understanding of the first 3 months following transplant, because complications related to transplantation often extend beyond the standard 30-day period after initial discharge. Because each patient is monitored quite closely after discharge until 1 year after receiving their transplant, it is unlikely that a posttransplant readmission to an outside hospital occurred without our knowledge. But caution needs to be used when applying these results to other centers. Variations in clinical care, physician practices, and patient characteristics need to be considered. For example, due to our rural location, most transplant patients live 2 or more hours away from our transplant center. In addition, our transplant patient population may differ from other centers. For example, most of our allogeneic patient population included unrelated donor

TABLE 4 Reasons for readmission of allogeneic and autologous patients

\section{Type of transplant}

\begin{abstract}
Reason for readmission, n (\%)
\end{abstract}

Fever

$\begin{array}{lcc}\text { Organism isolated } & 16 / 20(80) & 4 / 15(27) \\ \text { Graft-vs-host disease } & 5(13.9) & \text { na } \\ \text { Cardiopulmonary } & 2(5.6) & 4(17.4) \\ \text { Electrolyte abnormality } & 2(5.6) & 1(4.4) \\ \text { Gastrointestinal } & 1(2.8) & 2(8.7) \\ \text { Renal } & 1(2.8) & \text { na } \\ \text { Other } & 4(11.1) & 1(4.4)\end{array}$

na, not applicable

\section{Allogeneic (36 readmitted)}

$21(58.3)$

\section{(23 readmitted)}

$15(65.2)$ recipients $(65 \%)$ who received nonmyeloablative conditioning regimens ( $81 \%$ of allogeneic recipients). These features may not be characteristic of other centers. Finally, despite evaluating a large patient cohort, our patient population may be too small to identify high-risk characteristics that may predict readmission.

These results can be useful to the medical community, not just the transplant population, in several ways. First, the high readmission rate among allogeneic recipients indicates the critical need for posttransplant clinical pathways . For example, the most common reason for readmission was the development of a fever. Despite recommended prophylactic antimicrobials, our review of the medical records identified variability in the use, dose, and scheduling of antibiotics. A team-focused development, design, and implementation of a posttransplant clinical pathway could formalize patient care, improve efficiency and may decrease readmission rates. ${ }^{22,23}$ Second, research demonstrates that patient education prior to discharge is beneficial to preventing readmission. ${ }^{24}$ Prior to departure from the hospital, each of our patients receives discharge teaching from a transplant nurse coordinator, the care management team, and an inpatient transplant nurse. The addition of a pharmacist to the education process could reduce medication errors, increase compliance, and decrease readmission rates. ${ }^{25-27}$ Third, ongoing patient education that focused on continuity of care in the ambulatory clinic can also be advantageous. ${ }^{24-28}$ Our program is addressing each of these issues, along with 
regular phone calls by transplant-trained nurses to transplant patients after discharge from the hospital. We are also exploring the use of routinely scheduled messages, using e-mail and the electronic health record messaging system, to closely monitor patients' signs and symptoms after discharge. We are examining the use of telehealth appointments while the patient remains at home, to proactively treat a patient's new complaints early. Our goal is to use these methods to address signs and symptoms earlier and prevent a patient's readmission.

\section{References}

1. Tsai TC, Joynt KE, Orav EJ, Gawande AA, Jha AK. Variation in surgical-readmission rates and quality of hospital care. N Engl J Med. 2013;369:1134-1142.

2. Kocher RP, Adashi EY. Hospital readmissions and the Affordable Care Act: paying for coordinated quality care. JAMA. 2011;306:1794-1795.

3. Elixhauser A, Steiner C. Readmissions to US hospitals by diagnosis, 2010. Statistical Brief \#153. Healthcare Cost and Utilization Project (HCUP) Statistical Briefs [Internet]. http://www.ncbi.nlm.nih.gov/ books/NBK154385/. Published April 2013. Accessed September 4, 2015.

4. Dharmarajan K, Hsieh AF, Lin Z, et al. Hospital readmission performance and patterns of readmission: retrospective cohort study of Medicare admissions. Brit Med J. 2013;347:f6571.

5. Rauenzahn S, Truong Q, Cumpston A, et al. Predictors and impact of thirty-day readmission on patient outcomes and health care costs after reduced-toxicity conditioning allogeneic hematopoietic cell transplantation. Biol Blood Marrow Transplant. 2014;20:415-420.

6. Singh S, Lin YL, Kuo YF, Nattinger AB, Goodwin JS. Variation in the risk of readmission among hospitals: the relative contribution of patient, hospital and inpatient provider characteristics. J Gen Intern Med. 2014;29:572-578.

7. Krumholz HM, Merrill AR, Schone EM, et al. Patterns of hospital performance in acute myocardial infarction and heart failure 30day mortality and readmission. Circ Cardiovasc Qual Outcomes. 2009;2:407-413.

8. Pasquini MC, Zhu X. Current uses and outcomes of hematopoietic stem cell transplantation: 2014 CIBMTR Summary Slides. http:// www.cibmtr.org. Accessed September 9, 2015.

9. Lee SJ, Klar N, Weeks JC, Antin JH. Predicting costs of stem-cell transplantation. J Clin Oncol. 2000;18:64-71.

10. Khera N, Zeliadt SB, Lee SJ. Economics of hematopoietic cell transplantation. Blood. 2012;120:1545-1551.

11. Preussler JM, Denzen EM, Majhail NS. Costs and cost-effectiveness of hematopoietic cell transplantation. Biol Blood Marrow Transplant. 2012;18:1620-1628

12. Majhail NS, Mau LW, Denzen EM, Arneson TJ. Costs of autologous and allogeneic hematopoietic cell transplantation in the United States: a study using a large national private claims database. Bone
Marrow Transplant. 2013;48:294-300.

13. Saito AM, Cutler C, Zahrieh D, et al. Costs of allogeneic hematopoietic cell transplantation with high-dose regimens. Biol Blood Marrow Transplant. 2008;14:197-207.

14. Stranges E, Russo CA, Friedman B. Procedures with the most rapidly increasing hospital costs, 2004-2007. Statistical Brief \#82. Healthcare Cost and Utilization Project (HCUP) Statistical Briefs [Internet]. http://www.ncbi.nlm.nih.gov/books/NBK53597/. Published December 2009. Accessed May 21, 2015.

15. Sorror ML, Maris MB, Storb R, et al. Hematopoietic cell transplantation (HCT)-specific comorbidity index: a new tool for risk assessment before allogeneic HCT. Blood. 2005;106:2912-2919.

16. Pereira AA, Bhattacharya R, Carithers R, Reyes J, Perkins J. Clinical factors predicting readmission after orthotopic liver transplantation. Liver Transplantation. 2012;18:1037-1045.

17. McAdams-Demarco MA, Grams ME, Hall EC, Coresh J, Segev DL. Early hospital readmission after kidney transplantation: patient and center-level associations. Am J Transplant. 2012;12:3283-3288.

18. Bejanyan N, Bolwell BJ, Lazaryan A, et al. Risk factors for 30-day hospital readmission following myeloablative allogeneic hematopoietic cell transplantation (allo-HCT). Biol Blood Marrow Transplant. 2012;18:874-880.

19. Jaing TH, Tsay PK, Yang CP, Hung IJ, Wen YC, Tseng CK. Evaluation of readmission in children receiving allogeneic hematopoietic stem cell transplantation: an institutional experience. Transplant Proc. 2008;40: 3643-3645.

20. Moya R, Espigado I, Parody R, Carmona M, Marquez F, De Blas JM. Evaluation of readmissions in hematopoietic stem cell transplant recipients. Transplant Proc. 2006;38:2591-2592.

21. Mohan SR, Rybicki L, Smith SD, et al. Analysis of readmission after autologous HCT: predictive factors and clinical consequences. Blood. 2010;116:932a.

22. Kangovi S, Grande D. Hospital readmissions - not just a measure of quality. JAMA. 2011;306:1796-1797.

23. Kansagara D, Englander H, Salanitro A, et al. Risk prediction models for hospital readmission: a systematic review. JAMA. 2011;306:1688-1698.

24. Febryani I, Estrella JM, Brandert MK, Adornetto-Garcia DL. creating continuity of care: pre-admission transplant education. Biol Blood Marrow Transplant. 2010;16(2, suppl 2): S330.

25. Musgrave CR, Pilch NA, Taber DJ, et al. Improving transplant patient safety through pharmacist discharge medication reconciliation. Am J Transplant. 2013;13:796-801.

26. Ho P, Lambert-Kerzner A, Carey EP, et al. Multifaceted intervention to improve medication adherence and secondary prevention measures after acute coronary syndrome hospital discharge: a randomized clinical trial. JAMA Intern Med. 2014;174:186-193.

27. Kilcup M, Schultz D, Carlson J, Wilson B. Postdischarge pharmacist medication reconciliation: impact on readmission rates and financial savings. J Am Pharm Assoc (2003). 2013;53:78-84.

28. Jack BW, Chetty VK, Anthony D, et al. A reengineered hospital discharge program to decrease rehospitalization a randomized trial. Ann Int Med. 2009;150:178-187. 